\title{
O impacto emocional imposto pela ditadura da beleza: uma revisão narrativa
}

The emotional impact imposed by the dictatorship of beauty: a narrative review

El impacto emocional impuesto por la dictadura de la belleza: una revisión narrativa

Manuella da Silva Machado ${ }^{1 *}$, Isabela Costa Linhares ${ }^{1}$, Larissa Sant'Ana Brum ${ }^{1}$, Mariana Saracino de Almeida ${ }^{1}$, Márcia Barroso Werneck¹.

\section{RESUMO}

Objetivo: Revisar na literatura sobre o impacto emocional que a ditadura da beleza causa na sociedade contemporânea, a fim de que se possa construir um arcabouço teórico alicerçado e uniforme para agregar conhecimento e alcançar o bem-estar físico, mental, social e emocional. Métodos: O presente trabalho tratase de uma revisão integrativa de literatura embasado em evidências, cuja elaboração deu-se por meio das seguintes etapas: identificar um tema e selecionar a questão de pesquisa, buscar os artigos nas bases de dados digitais e estabelecer critérios de inclusão e exclusão com posterior análise e discussão dos resultados obtidos nos periódicos. Resultados: A sociedade do espetáculo faz com que haja uma espetacularização da vida e uma progressiva exibição do eu, trazendo como consequência a alienação e a apreciação do que é extrínseco, tornando o intrínseco e as reflexões introspectivas dispensáveis. Considerações finais: Considera-se que a busca desenfreada por um corpo perfeito, faz com que as pessoas se submetam a sacrifícios e a procedimentos estéticos, e quando não conseguem atingir o padrão de beleza ideal, sentemse frustradas, desencadeando assim, sentimentos de impotência, os quais podem romper a linha tênue entre o saudável e o patológico.

Palavras-chave: Beleza, Imagem corporal, Mídia social, Sociedade.

\begin{abstract}
Objective: Review in the literature about the emotional impact that the dictatorship of beauty causes in contemporary society, so that a foundational and uniform theoretical framework can be built to add knowledge and achieve physical, mental, social and emotional well-being. Methods: The present work is an integrative review of evidence-based literature, which was elaborated through the following steps: identify a theme and select the research question, search the articles in digital databases and establish inclusion and exclusion criteria with subsequent analysis and discussion of the results obtained in the journals. Results: The society of the show causes there to be a spectacularization of life and a progressive display of the $i$, bringing as consequence the alienation and appreciation of what is extrinsic, making the intrinsic and introspective reflections expendable. Final considerations: It is considered that the unbridled search for a perfect body causes people to submit to sacrifices and aesthetic procedures, and when they cannot reach the ideal standard of beauty, they feel frustrated, thus triggering feelings of impotence, which can break the fine line between the healthy and the pathological.
\end{abstract}

Keywords: Beauty, Body image, Social media, Society.

\section{RESUMEN}

Objetivo: Reseñar en la literatura sobre el impacto emocional que la dictadura de la belleza provoca en la sociedad contemporánea, de manera que se pueda construir un marco teórico fundacional y uniforme para

1 Universidade de Vassouras (UV), Vassouras - RJ. *E-mail: manumachadoo16@gmail.com 
sumar conocimiento y lograr el bienestar físico, mental, social y emocional. Métodos: El presente trabajo es una revisión integradora de la literatura basada en la evidencia, que fue elaborada a través de los siguientes pasos: identificar un tema y seleccionar la pregunta de investigación, buscar los artículos en bases de datos digitales y establecer criterios de inclusión y exclusión con posterior análisis y discusión de los resultados obtenidos en las revistas. Resultados: La sociedad del espectáculo hace allí una espectacularización de la vida y un despliegue progresivo de la i, trayendo como consecuencia la alienación y apreciación de lo extrínseco, haciendo prescindibles las reflexiones intrínsecas e introspectivas. Consideraciones finales: Se considera que la búsqueda desenfrenada de un cuerpo perfecto, hace que las personas se sometan a sacrificios y procedimientos estéticos, y cuando no pueden alcanzar el estándar ideal de belleza, se sienten frustradas, desencadenando así sentimientos de impotencia, que pueden romper la delgada línea entre lo saludable y lo patológico.

Palabras clave: Belleza, Imagen corporal, Redes sociales, Sociedad.

\section{INTRODUÇÃO}

Beleza: essa é a palavra de ordem que rege mundialmente a sociedade do espetáculo. Tudo gira em torno do que é, está, ou irá se tornar belo e perfeito (MACHADO RC e NORONHA IL, 2011). Mas afinal de contas, a que beleza estamos nos referindo? Imediatamente, a resposta estaria vinculada à descrição das qualidades estéticas compreendidas e enaltecidas como belas, que, por sua vez, são evidenciadas nos atributos físicos dos seres humanos tidos como padrão de beleza pela sociedade contemporânea (DE SAMPAIO RPA e FERREIRA RF, 2009).

Nesse contexto, a beleza ditada pela sociedade seria equivalente ao menor percentual de gordura corporal possível, nádegas e seios fartos e empinados, músculos evidenciados, pele bronzeada, lábios volumosos, ausência de celulite, de estrias e de qualquer outra mancha na pele ou característica que evidencie idade, como rugas, flacidez e marcas de expressão (DE SAMPAIO RPA e FERREIRA RF, 2009).

Diante disso, os indivíduos tornam-se escravos da balança, dos manequins cada vez mais reduzidos, dos cabelos predominantemente lisos, dos procedimentos estéticos e mentes cada vez mais limitadas; ou seja, esses sujeitos sociais acabam se tornando vítimas em potencial desse mal, que infelizmente, ainda está longe de chegar ao fim (MACHADO RC e NORONHA IL, 2011).

Assim sendo, a sociedade do espetáculo pode ser definida como consumo de imagens fabricadas pela indústria cultural, o simulacro, cujas imagens de beleza constroem uma realidade enganosa, uma "realidade falsa", mas que é vivida e encarada como uma realidade verdadeira (VISCARDI AW, et al., 2012; DE PAIVA JZ e DE OLIVEIRA RJF, 2015).

Ou seja, temos uma sociedade voltada para aparência, onde só sobrevive quem é digno de ser notado, o exibicionismo social é personificado nas celebridades (atores/atrizes, blogueiros/blogueiras etc.), indivíduos supostamente superiores aos espectadores, que se tornam exemplos padronizados de beleza que dominam o espetáculo, convencendo o espectador que contempla e se identifica a desejar ser como elas (VISCARDI AW, et al., 2012).

Sendo assim, os espectadores do espetáculo tornam-se seres alienados que seguem os ditames midiáticos, que seduzem de forma inconsciente e hedonista, estimulando o consumo de produtos e procedimentos estéticos para satisfazer a autoimagem, em uma busca obsessiva por um padrão de beleza, que em sua maioria, é utópico (VISCARDI AW, et al., 2012).

Os veículos de comunicação de massa manipulam os comportamentos sociais, modelando a maneira pela qual os indivíduos se relacionam, aprendem, compram e cuidam do corpo. Dentre eles, podemos citar as mídias sociais, que por sua vez, atualizam constantemente as práticas arbitrárias que atuam nitidamente sobre a materialidade do corpo, levando à construção de uma identidade corporal midiatizada (DE SOUZA MRR, et al., 2013). Portanto, se antes desse bombardeio midiático, as identidades eram sólidas, atualmente, 
elas são fluidas e "líquidas" provocando nos sujeitos sociais uma "crise de identidade" (PEREIRA TMA e LEITE MRB, 2009).

Perante o exposto, não somente as identidades dos adultos são afetadas, mas também as de crianças e adolescentes. Exemplo disso, são as representações da boneca Barbie na cultura lúdica, pois a boneca personifica a fantasia de um mundo encantador, um ideal de beleza feminino, branco, esbelto e loiro de modo que afeta a construção das identidades infantis (CECHIN MBC e SILVA T, 2013).

Mediante os argumentos supracitados, estar no padrão de beleza midiático difundido do belo, do esguio e do juvenil, produz um fenômeno crescente de culto ao corpo, conduzindo a uma incompatibilidade que ocorre quando não há correspondência entre a imagem corporal produzida pela sociedade do espetáculo e a imagem corporal real da maioria dos indivíduos. Logo, os indivíduos, por meio de sacrifícios, buscam atingir tais padrões e quando não conseguem, há uma desvalorização do sujeito, o que abre margem para o surgimento de baixa autoestima, depressão, transtornos psicológicos como vigorexia e transtornos alimentares como anorexia e bulimia, resultando em frustração e sofrimento psíquico, podendo inclusive, levar o indivíduo à morte (GOETZ ER, et al., 2008; SUENAGA C, et al., 2012).

Assim sendo, este estudo teve como propósito levar os seres humanos a refletir se a busca obsessiva pelo ideal estético perfeito é verdadeiramente mais relevante do que ter identidade própria, ser autêntico, pensar, sentir e agir por si mesmo e ser saudável, o que envolve o bem-estar físico, psíquico e social.

\section{MÉTODOS}

O presente trabalho trata-se de uma revisão integrativa de literatura embasado em evidências, cujo objetivo diz respeito à reflexão da problemática em questão, a fim de que se possa agregar conhecimento e alcançar o bem-estar físico, mental, social e emocional. Assim sendo, as etapas para construir essa revisão foram: identificar um tema e selecionar a questão de pesquisa, buscar os artigos nas bases de dados digitais e estabelecer critérios de inclusão e exclusão com posterior análise e discussão dos resultados obtidos nos periódicos.

Foram buscados artigos publicados no período de 2016 a 2021; as bases de dados utilizadas foram Google Acadêmico, Literatura Latino-americana e do Caribe em Ciências da Saúde (LILACS) e Scientific Electronic Library Online (Scielo). Utilizando os seguintes descritores: padrão de beleza, preço da beleza, mídia social e beleza, estereótipo e também ideal de beleza no Google Acadêmico, LILACS e Scielo em português, e percepção de beleza apenas no Google Acadêmico.

Na base de dados Scielo, as buscas resultaram no total de 338 artigos, porém após utilizar o filtro coleções Brasileiras, restringiu-se para 168 artigos. No Google acadêmico, foram encontrados ao todo 722.300 artigos, contudo, após aplicar o filtro período específico de 2016 a 2021, reduziu-se para 107.900 artigos, sendo selecionados apenas os artigos que estavam de acordo com a relevância para o tema. Por fim, na LILACS, foram encontrados no total 532 artigos, todavia, com a aplicação do filtro período específico de 2016 a 2021 , encurtou-se para 127 artigos.

De todas as publicações encontradas nas três bases de dados pesquisadas, foram excluídas as duplicadas, além disso, estabeleceu-se critérios de inclusão e exclusão, e após a aplicação dos mesmos, apenas 7 artigos foram utilizados. Dentre os critérios de inclusão utilizados temos: estudos disponíveis gratuitamente e que respondem à questão norteadora. A respeito dos critérios de exclusão temos: duplicação entre as bases e artigos fora do tema abordado. Ademais, todas as referências dos 7 periódicos selecionados foram averiguadas por completo, a fim de ampliar o arcabouço teórico deste trabalho. A seguir, a Figura 1 ilustra quais critérios de inclusão e exclusão foram utilizados para filtrar as publicações. 
Figura 1- Fluxograma da apuração dos artigos para sintetizar esta revisão.

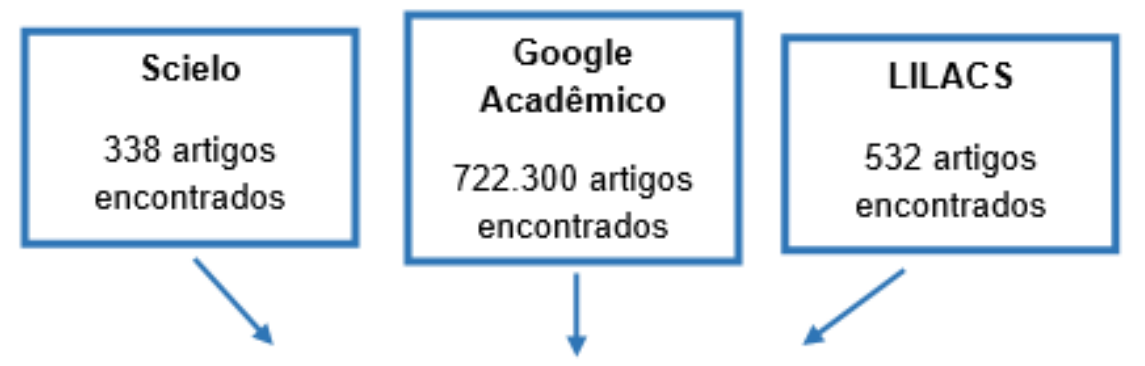

Filtros: Coleções Brasileiras (Scielo) e período específico de 2016 a 2021 (Google Acadêmico e LILACS).

Critérios de Inclusão: estudos disponíveis gratuitamente e que respondem à questão norteadora.

Critérios de Exclusão: duplicação entre as bases e fora do tema abordado.

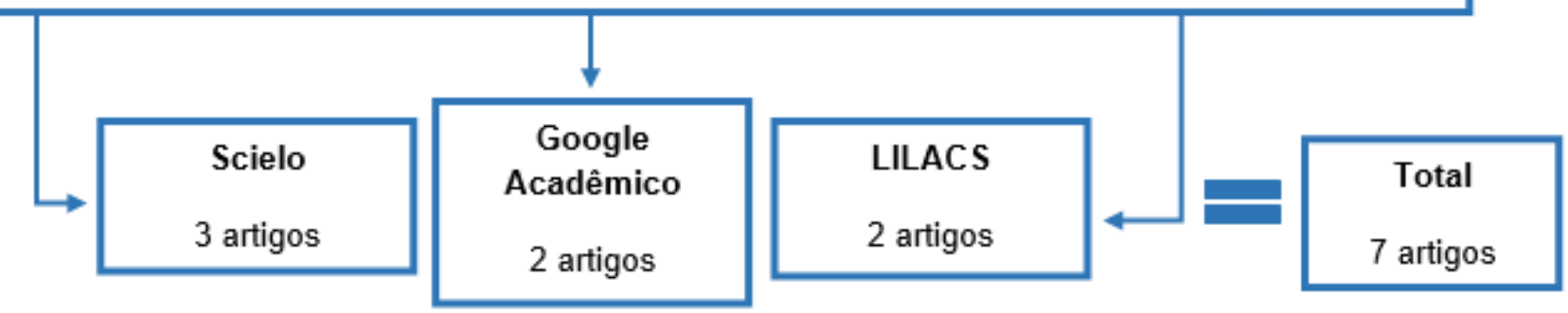

Fonte: MACHADO MS, et al., 2021

\section{RESULTADOS E DISCUSSÃO}

À princípio, partindo da seleção de 7 artigos com descritores específicos e verificados como pertinentes ao que este trabalho se destina, cada um deles foi arquivado para pesquisa, exploração e análise crítica. Por conseguinte, foi realizada uma leitura detalhada desses artigos selecionados e além disso, eles também foram minuciosamente revisados e examinados, apurando-se os pontos mais relevantes no que diz respeito à temática abordada.

Esses artigos variam entre os anos de 2016 a 2021, sendo todos nacionais e abrangendo as regiões Sudeste, Sul e Nordeste. A partir dos 7 artigos analisados, podemos inferir que apesar dos mais variados perfis epidemiológicos, envolvendo crianças, adolescentes, adultos e idosos, circula entre eles um padrão estético ideal imposto pela sociedade do espetáculo e difundido por grandes veículos de comunicação em massa, destacando-se dentre eles as mídias sociais.

Em relação às redes sociais, o Instagram é comumente conhecido como uma rede social "egocêntrica", em que a imagem do corpo do usuário em lugares atraentes se destaca. Além disso, ser blogueiro se tornou profissão para alguns jovens, de forma que alguns deles conseguem ficar famosos e alcançar status de celebridade, representando assim, uma personalidade ou estilo de vida que os seguidores dessas pessoas gostariam de ter. Ademais, determinadas publicações e produtos divulgados por esses digital influencers podem condicionar comportamentos não saudáveis nos âmbitos alimentares e estéticos dos usuários expostos a eles, e também, podem levar à difusão de uma imagem ideal de corpo e beleza (STOLARSKI G, et al., 2018).

Vale ressaltar, que essa beleza padronizada, no entanto, trata-se de um perfil inatingível, fazendo com que o corpo virtual, ou seja, aquele criado imageticamente pela mídia, e o corpo real, sejam extremamente distintos, levando o indivíduo a cair na obsessão da corpolatria, direcionando sua vida e relações em busca da construção de um corpo perfeito. Dessa forma, o espectador desse espetáculo, de modo responsivo, passa 
a fazer o consumo de determinados bens, de modo a diminuir a diferença entre o corpo ideal/virtual e o corpo real, resultando em idas a academias, salões de beleza, clínicas de cirurgiões plásticos e centros de estética. Mediante a esse contexto, foi observado que o Brasil é o segundo classificado no mundo em relação ao número de academias e o quarto em número de clientes, segundo a revista da Associação Brasileira de Academia (ACAD Brasil) (LOPES AF e DE MENDONÇA ES, 2016).

Para mais, de acordo com os dados divulgados pela Sociedade Internacional de Cirurgia Plástica e Estética, o Brasil ocupa o segundo lugar no ranking mundial de procedimentos de cirurgia plástica, sendo as cirurgias mais populares a lipoaspiração e abdominoplastia, ambas relacionadas de forma direta com a redução do volume corporal, fortalecendo ainda mais a premissa da magreza como padrão ideal de beleza (LÔBO ILB, et al., 2020).

Em suma, essa sociedade de consumo, faz com que haja uma espetacularização da vida, de tendências fluidas e uma progressiva exibição do eu, o que traz como consequência a alienação e a apreciação do que é extrínseco, tornando o intrínseco e as reflexões introspectivas dispensáveis (DE OLIVEIRA MR e DE MACHADO JSA, 2021). Em vista disso, quando o ideal estético não é alcançado, surgem sentimentos de insatisfação corporal, o que desencadeia respostas emocionais negativas que afetam diretamente a saúde mental e o bem-estar dos indivíduos (LÔBO ILB, et al., 2020).

Dessa forma, depreende-se que os dados obtidos por meio dos artigos selecionados complementam-se, demonstrando que apesar de os perfis epidemiológicos serem diversos, existe uma essência comum entre eles, tornando-os extremamente relevantes para atual conjuntura em que vivemos, o que é corroborado através das informações dispostas no Quadro 1, para título de análise e exemplificação do que foi exposto. 
Quadro 1 - Resultados obtidos após análise minuciosa dos periódicos.

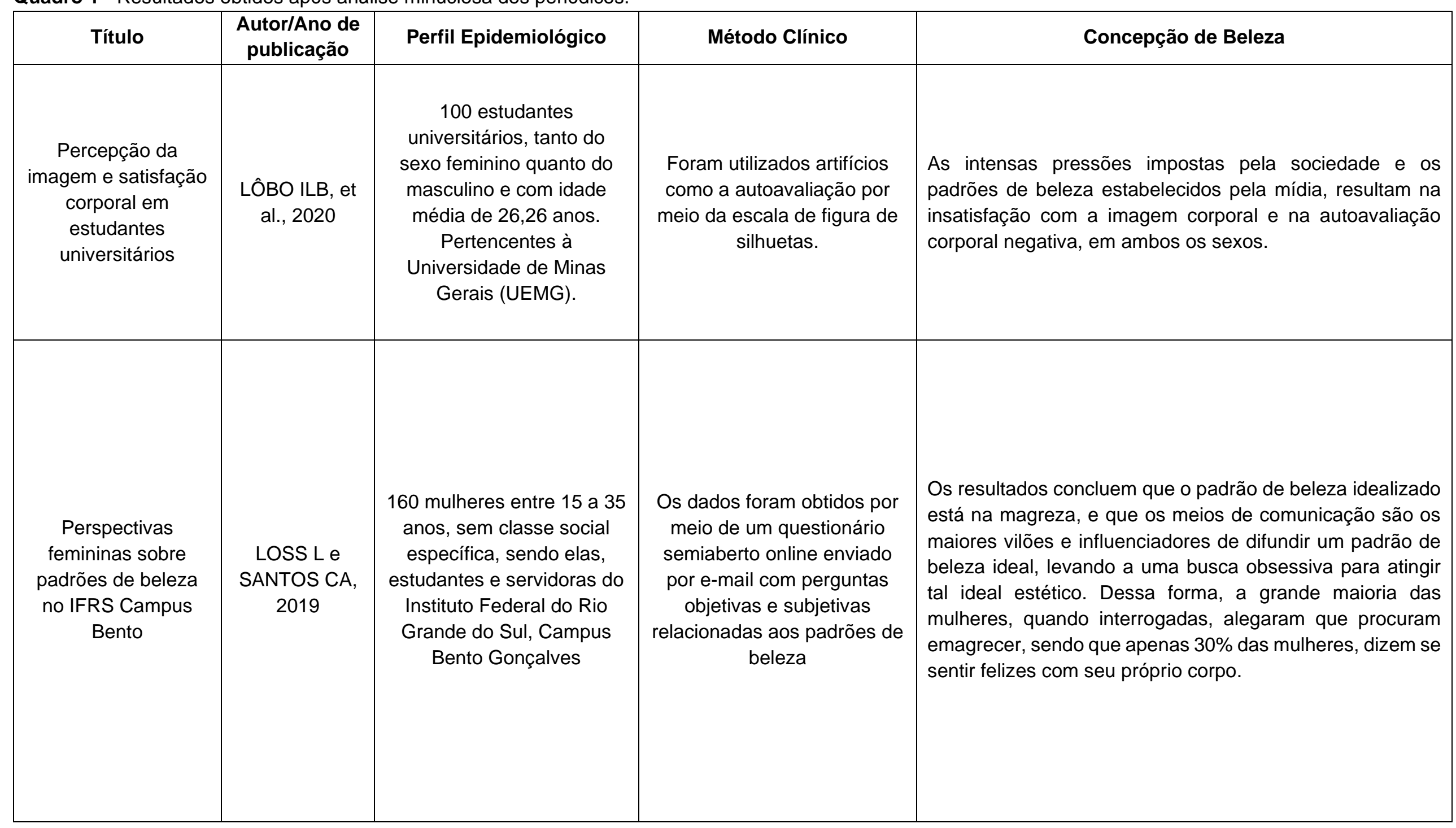




\begin{tabular}{|c|c|c|c|c|}
\hline Título & $\begin{array}{l}\text { Autor/Ano de } \\
\text { publicação }\end{array}$ & Perfil Epidemiológico & Método Clínico & Concepção de Beleza \\
\hline $\begin{array}{l}\text { O insustentável peso } \\
\text { da autoimagem: (re) } \\
\text { apresentações na } \\
\text { sociedade do } \\
\text { espetáculo }\end{array}$ & $\begin{array}{l}\text { DE OLIVEIRA } \\
\text { MR e DE } \\
\text { MACHADO } \\
\text { JSA, } 2021\end{array}$ & $\begin{array}{c}13 \text { adolescentes, sendo } 10 \\
\text { do sexo feminino e } 3 \text { do } \\
\text { sexo masculino com faixa } \\
\text { etária entre } 15 \text { a } 19 \text { anos. } \\
\text { Pertencentes a uma escola } \\
\text { pública estadual localizada } \\
\text { no centro oeste de Minas } \\
\text { de Gerais. }\end{array}$ & $\begin{array}{l}\text { Foram utilizadas entrevistas } \\
\text { com um roteiro } \\
\text { semiestruturado para a } \\
\text { obtenção de dados. As } \\
\text { questões desse roteiro } \\
\text { abordavam temas como: } \\
\text { percepção da autoimagem, } \\
\text { padrões de corpo e beleza } \\
\text { ideal e influências das mídias } \\
\text { sociais na autoimagem. }\end{array}$ & $\begin{array}{l}\text { Devido ao padrão de beleza ideal ditado pela sociedade e } \\
\text { ao poder das mídias sociais, os adolescentes, na tentativa } \\
\text { de serem aceitos socialmente, sentem-se na } \\
\text { obrigatoriedade de atender a esse padrão, logo, isso } \\
\text { provoca uma distorção da autoimagem corporal que o } \\
\text { adolescente tem de si. Dessa forma, muitos mencionam } \\
\text { que estão insatisfeitos com seus os corpos e alegam } \\
\text { possuir desejo de mudança estética, sendo o nariz o que } \\
\text { mais incomoda, seguido do peso, cicatrizes, manchas de } \\
\text { espinha, estrias e altura. }\end{array}$ \\
\hline $\begin{array}{l}\text { Blogueiros fitness no } \\
\text { Instagram: o corpo e } \\
\text { o merchandising } \\
\text { editorial de } \\
\text { suplementos } \\
\text { alimentares }\end{array}$ & $\begin{array}{l}\text { STOLARSKI } \\
\text { G, et al., } 2018\end{array}$ & $\begin{array}{l}10 \text { perfis de blogueiros } \\
\text { fitness populares do Brasil, } \\
\text { sendo } 6 \text { femininos e } 4 \\
\text { masculinos com o mínimo } \\
\text { duzentos mil seguidores }\end{array}$ & $\begin{array}{l}\text { Acompanhamento desses } \\
\text { perfis no Instagram por } 15 \\
\text { dias consecutivos. }\end{array}$ & $\begin{array}{l}\text { Conclui-se que as postagens realizadas por esses } \\
\text { blogueiros reforçam o ideal de beleza presente na mídia } \\
\text { de massa, além disso, nelas, há intenção publicitária de } \\
\text { vender os produtos/serviços a elas associados. Inclusive, } \\
\text { há uma alta frequência de postagens, principalmente com } \\
\text { fotos do corpo magro e malhado ou de partes dele, } \\
\text { lembrando que o Instagram é comumente visto como um } \\
\text { app que melhora a qualidade da imagem, 'maquiando-a' } \\
\text { por meio de filtros e edições, logo, os usuários podem } \\
\text { interpretar essas imagens como hiper-reais criando um } \\
\text { ideal de beleza utópico. }\end{array}$ \\
\hline
\end{tabular}




\begin{tabular}{|c|c|c|c|c|}
\hline Título & $\begin{array}{l}\text { Autor/Ano de } \\
\text { publicação }\end{array}$ & Perfil Epidemiológico & Método Clínico & Concepção de Beleza \\
\hline $\begin{array}{l}\text { Ser jovem, ser belo: } \\
\text { a juventude sob } \\
\text { holofotes na } \\
\text { sociedade } \\
\text { contemporânea }\end{array}$ & $\begin{array}{c}\text { LOPES AF e } \\
\text { DE } \\
\text { MENDONÇA } \\
\text { ES, } 2016\end{array}$ & $\begin{array}{l}10 \text { jovens, sendo } 5 \text { homens } \\
\text { e } 5 \text { mulheres com faixa } \\
\text { etária entre } 18 \text { a } 29 \text { anos } \\
\text { de idade, sendo } \\
\text { frequentadores de uma } \\
\text { academia de classe média } \\
\text { alta, situada numa cidade } \\
\text { do interior do Nordeste } \\
\text { brasileiro. }\end{array}$ & $\begin{array}{c}\text { Foram utilizadas entrevistas } \\
\text { semiestruturadas, e a partir } \\
\text { delas, obteve-se } 3 \text { categorias } \\
\text { de discussão: } 1 \text { - relação do } \\
\text { jovem com o corpo; } 2 \text { - } \\
\text { concepção juvenil de beleza; } \\
\text { e 3- sentidos atribuídos aos } \\
\text { valores propagados pela } \\
\text { mídia. }\end{array}$ & $\begin{array}{l}\text { Constata-se que as narrativas dos jovens entrevistados são } \\
\text { repletas de ambiguidades e contradições, pois ao mesmo } \\
\text { tempo que eles dizem não serem produtos dessa cultura do } \\
\text { consumo, ou seja, não acharem possível atingir o ideal } \\
\text { estético difundido pela mídia, eles também apontam como } \\
\text { cuidam e se preocupam com o próprio corpo, muitas vezes, } \\
\text { julgando o corpo do outro e mostrando que ter um corpo } \\
\text { belo significa aptidão para ter sucesso na vida social, } \\
\text { profissional e afetiva. Em síntese, apesar de criticar as } \\
\text { exigências sociais quanto aos padrões de beleza, eles } \\
\text { também buscam por esse mesmo ideal, mostrando que há } \\
\text { uma naturalização do padrão beleza e este, se difunde sem } \\
\text { que percebamos. }\end{array}$ \\
\hline $\begin{array}{c}\text { Percepção de } \\
\text { beleza, autoestima e } \\
\text { bem-estar de idosos }\end{array}$ & $\begin{array}{c}\text { DE ONESKO } \\
\text { JA, et al., } 2017\end{array}$ & $\begin{array}{l}15 \text { idosos, sendo } 3 \text { homens } \\
\text { e } 12 \text { mulheres na faixa } \\
\text { entre } 60 \text { a } 80 \text { anos. Todos } \\
\text { realizaram as atividades } \\
\text { em um Centro de Medicina } \\
\text { Preventiva privada para } \\
\text { idosos na cidade de } \\
\text { Maringá/PR. }\end{array}$ & $\begin{array}{c}\text { Foram realizados } 2 \\
\text { encontros em grupo por meio } \\
\text { de jogos, brincadeiras, } \\
\text { visualização de figuras e } \\
\text { perguntas realizadas ao } \\
\text { grupo que respondia à } \\
\text { medida que as conversas } \\
\text { iam rolando. }\end{array}$ & $\begin{array}{l}\text { Os idosos não deram muita relevância ao aspecto físico, } \\
\text { evidenciando mais a parte espiritual e de caráter, já as } \\
\text { idosas se sentiram mais incomodadas com o corpo, com as } \\
\text { linhas de expressão e rugas na face. Todavia, no geral, eles } \\
\text { alegaram que a beleza é um fator importante sim, contudo, } \\
\text { acreditam mais ainda na importância em aceitar o corpo } \\
\text { atual, a beleza e a experiência que acompanham essa fase } \\
\text { da vida. Logo, a concepção de beleza para os idosos } \\
\text { continua sendo um aspecto subjetivo importante para que } \\
\text { mantenham a autoestima elevada, pois o autocuidado, as } \\
\text { atividades rotineiras, a família unida, a liberdade de realizar } \\
\text { suas atividades físicas, leva-os ao bem-estar geral e a } \\
\text { serem mais felizes e ativos na vida. }\end{array}$ \\
\hline
\end{tabular}




\begin{tabular}{|c|c|c|c|c|}
\hline Título & $\begin{array}{l}\text { Autor/Ano de } \\
\text { publicacão }\end{array}$ & Perfil Epidemiológico & Método Clínico & Concepção de Beleza \\
\hline $\begin{array}{l}\text { Percepções de } \\
\text { crianças sobre } \\
\text { padrões de beleza }\end{array}$ & $\begin{array}{l}\text { BUSS J e } \\
\text { STOLTZ T, } \\
2020\end{array}$ & $\begin{array}{c}50 \text { crianças, com idades de } \\
4,6,8,10 \text { e } 12 \text { anos, } \\
\text { pertencentes à instituição } \\
\text { pública do município de } \\
\text { Curitiba. }\end{array}$ & $\begin{array}{l}\text { Método clínico Jean Piaget. } \\
\text { Os colaboradores foram } \\
\text { solicitados a fazer um } \\
\text { desenho, visualizar } \\
\text { fotografias e responder a } \\
\text { questões relacionadas a } \\
\text { padrões de beleza. } \\
\text { Os indivíduos das fotografias } \\
\text { apresentavam as seguintes } \\
\text { características: 1- acima do } \\
\text { peso, 2- loiro de olho claro, } \\
\text { 3- com óculos de grau; 4- } \\
\text { afrodescendente; e 5- abaixo } \\
\text { do peso. }\end{array}$ & $\begin{array}{l}\text { Crianças de } 4 \text { anos: } \\
\text { Quanto ao padrão de beleza, disseram que uma pessoa } \\
\text { bonita é aquela que desenharam (pai, mãe, amigo etc.). } \\
\text { uma pessoa feia é aquela que tem comportamentos } \\
\text { negativos como, morder, brigar, bater etc. } \\
\text { Crianças de } 6 \text { anos: } \\
\text { Quanto ao padrão de beleza, } 7 \text { crianças disseram que uma } \\
\text { pessoa bonita é aquela que brinca e não briga, e } 3 \\
\text { relacionaram beleza com roupa, cabelo e maquiagem. } 8 \\
\text { crianças disseram que uma pessoa feia é aquela que é } \\
\text { brava e } 2 \text { relacionaram feiura com roupas rasgadas, velhas } \\
\text { e etc. } \\
\text { Crianças de } 8 \text { anos: } \\
\text { Quanto ao padrão de beleza, } 4 \text { crianças priorizaram a } \\
\text { beleza interior, } 2 \text { ligaram a beleza a fatores externos } \\
\text { (maquiagem, roupa nova etc.) e } 4 \text { não souberam explicar. } \\
4 \text { crianças disseram que uma pessoa feia é aquela que não } \\
\text { cuida do cabelo e usa roupas rasgadas, } 4 \text { crianças } \\
\text { disseram que uma pessoa mal-educada é feia e } 2 \text { não } \\
\text { souberam explicar. } \\
\text { Crianças de } 10 \text { anos: } \\
\text { Quanto ao padrão de beleza, disseram que uma pessoa } \\
\text { bonita é simples, inteligente, educada, na moda, com estilo } \\
\text { etc. Disseram que uma pessoa feia é aquela que não cuida } \\
\text { da pele, do cabelo, é desarrumada, sem dente, que fuma } \\
\text { etc. } \\
\text { Crianças de } 12 \text { anos: } \\
\text { Todas as crianças quando interrogadas sobre o que é uma } \\
\text { pessoa bonita ou feia, diferenciaram beleza intrínseca de } \\
\text { extrínseca e alegaram que a beleza interior é a primordial. }\end{array}$ \\
\hline
\end{tabular}

Fonte: MACHADO MS, et al., 2021. 
Os corpos são produções e, como tal, são apresentados de formas distintas em cada momento histórico, ou ainda de forma heterogênea, mas em um mesmo período (VIEIRA CAL e BOSI MLM, 2013). Em virtude disso, em cada época, o grupo social com maior capacidade de influenciar o modo de pensar dos indivíduos, é responsável por confeccionar um modelo de imagem corporal considerada bela, o qual será imposto e rapidamente alastrado pela sociedade vigente (DE SENA RMC, et al., 2019).

Dessa forma, observa-se que a beleza aparece sempre como um aspecto e/ou dimensão associada à construção da imagem corporal, imprimindo-lhe muitas das vezes, atributos de uma perfeição quase divinal, daquilo que é belo e bom, mas também relativa, já que os homens, mesmo sendo meros mortais, são incentivados a persegui-la e alcançá-la. Esse pensamento ainda perpetua na sociedade contemporânea em que vivemos, vigorando assim, uma sedução narcísica de verdadeira perseguição pela satisfação com a aparência corporal. Diante disso, é intrigante perceber que mesmo a beleza sendo um conceito tão abstrato, ela ainda se encontra amarrada à produção de estereótipos padronizados em diferentes contextos históricos (DE SENA RMC, et al., 2019).

Um novo momento na história da beleza foi instaurado, pois a influência da mídia na confecção do corpo ideal ganhou poder e ampliou a paixão pela estética, expandindo assim, o consumo de produtos que garantem uma imagem corporal bela, tornando a aparência física algo primordial da identidade feminina. Nesse contexto, se, historicamente, as mulheres importavam-se com sua beleza, na atualidade, ser/estar bela é uma incumbência da mulher imposta pela sociedade do espetáculo (DE SOUZA MRR, et al., 2013).

Dessa maneira, a busca por padrões estéticos deixou de ser uma escolha e passou a ser uma obrigação moral, da qual, a mulher deve se dedicar e se sacrificar o suficiente para conquistar, ou seja, a beleza passa a ser situada como uma questão de esforço pessoal, um critério que precisa ser alcançado por todas, como atributo dessa mulher moderna, emancipada e independente. Diante ao exposto, o corpo deixa de ser pensado na sua complexidade e incorporalidade e passa a ser um meio de consumo, que gera mais consumo (DE SOUZA MRR, et al., 2013).

A sociedade do espetáculo assiste fascinada à passagem dos "corpos perfeitos", que invadem gradativamente todos os espaços da vida contemporânea. A perspectiva que os indivíduos têm de corpo ideal mediante a esses padrões de beleza é o que supostamente interliga uma diversidade de fenômenos cada vez mais comuns, como a maior ocorrência de bulimia e anorexia, aumento de idas as academias e ascensão do número de cirurgias plásticas estéticas (NETO PP e CAPONI SNC, 2007).

Esse aumento da busca pela cirurgia plástica estética merece ênfase pelo impacto que as modificações corporais, propostas pela Medicina da Beleza, causam em relação à autoimagem e, também, pela posição que a medicina ocupa na sociedade, de difusora de "verdades científicas". De uma forma geral, os indivíduos sentem-se frustrados antes das intervenções cirúrgicas e da melhora da autoestima, porém o que a Cirurgia Plástica Estética não "conta" é que os novos recortes corporais provenientes dessas cirurgias definem novos padrões estéticos, que criam um ciclo vicioso, cuja insatisfação corporal leva à cirurgia plástica, e o corpo pós-cirúrgico torna-se um ideal que leva outras pessoas a ficarem insatisfeitas com os seus corpos e desejarem a cirurgia plástica também (NETO PP e CAPONI SNC, 2007).

Nesse contexto, o que faz com que as pessoas se sintam melhor e com autoestima elevada após a intervenção cirúrgica, é que a medicina da beleza ao transmitir a noção de integralidade em saúde como o bem-estar físico, mental e social, facilita a aceitação das práticas cirúrgicas, uma vez que esses indivíduos subentendem $\mathrm{o}$ ato cirúrgico como algo que trará benefícios para sua saúde (NETO PP e CAPONI SNC, 2007).

É importante ressaltar que apesar da maior parte dos estudos sobre padrão de beleza girarem em torno dos adultos, a supervalorização da beleza pela mídia afeta as crianças também, principalmente as do sexo feminino, pois o grande interesse mercadológico das mídias implanta desejos de práticas de embelezamento nas crianças, caracterizando-as como fortes consumidoras. Dito isso, as crianças têm sua identidade corporal demasiadamente afetada, pois as mesmas constroem seus discursos através de vivencias e aprendizados, tanto da família, quanto da escola e das redes sociais (BUSS J e STOLTZ T, 2020). 
Ademais, a percepção da beleza em idosos também é pouco referenciada em estudos científicos, no entanto, isso interfere na qualidade de vida e na autoestima dos mesmos, pois além das mudanças corporais, o envelhecimento traz também alterações psicológicas e emocionais que podem provocar uma crise de identidade (baixa autoestima e autoimagem) nos idosos. Dessa maneira, é de suma importância que os referencias de beleza sejam ressignificados na terceira idade, de modo que se tornem sinônimos de autocuidado e de bem-estar geral (DE ONESKO JA, et al., 2017).

Com o passar dos anos a imagem corporal é considerada cada vez mais relevante, pois reflete as essências, as ambições e as aflições do ser humano. Na atualidade, a busca pelo ideal estético perfeito tem se tornado algo comum no cotidiano, juntamente com cobranças que os indivíduos têm feito a si mesmos para atingir esse padrão de beleza utópico, em vista disso, determinadas pesquisas mostram que a maior parte da sociedade já sofreu ou ainda sofre com a busca pela perfeição (LOSS L e SANTOS CA, 2019).

Portanto, em face do "culto ao corpo", as pessoas têm perdido o seu "eu", a sua própria identidade, voltando o centro da esfera da vida para a imagem corporal, ou seja, seu próprio físico. É neste novo lugar, o lugar das manchas de espinha; pregas; estrias; flacidez; gordurinhas; sobrepeso; linhas de expressão; "culotes"; excesso de pelos, cabelos rebeldes etc., que o físico e as "imperfeições" são incansavelmente e impreterivelmente vigiados, controlados, temidos de maneira fóbica, importuna e descontrolada (NETO PP e CAPONI SNC, 2007).

Logo, não se trata apenas da busca desenfreada por um corpo "sarado", esbelto ou qualquer padrão pretendido, mas também a procura de uma mente livre de sofrimento. Cada pessoa que tenta modificar sua aparência em busca de valorização e aceitação na sociedade do espetáculo, seja pela submissão ou pela subversão da ordem vigente, acaba perdendo o controle de seu próprio corpo, se tornando assim, mais um mero espectador do espetáculo (HEINZELMANN FL, et al., 2014).

\section{CONSIDERAÇÕES FINAIS}

Em suma, é importante salientar que a espetacularização do corpo pode levar ao rompimento da linha tênue entre o saudável e o patológico, sendo assim, este estudo tem como pretensão levar os indivíduos, em destaque os profissionais de saúde, a refletir criticamente a respeito do poder que os veículos de comunicação exercem na formação e na propagação de ideais estéticos, os quais, modelam e/ou definem o vestuário, as atividades físicas, as dietas e os procedimentos estéticos que compõem a imagem corporal dos indivíduos, a qual interfere de forma direta ou indiretamente no processo saúde/doença. Além disso, há uma carência de referências recentes acerca do foi discorrido, portanto é mister estimular novos estudos acerca dessa proposição para que então seja melhor explorada na comunidade científica.

\section{REFERÊNCIAS}

1. BUSS J, STOLTZ T. Percepções de crianças sobre padrões de beleza. Psicologia Escolar e Educacional, 2020; 24.

2. CECHIN MBC, DA SILVA T. Assim falava Barbie: uma boneca para todos e para ninguém. Fractal: Revista de Psicologia, 2012; 24:623-638.

3. DE OLIVEIRA MR, DE MACHADO JSA. O insustentável peso da autoimagem:(re) apresentações na sociedade do espetáculo. Ciência \& Saúde Coletiva, 2021; 26: 2663-2672.

4. DE ONESKO JA, et al. Percepção de beleza, autoestima e bem-estar de idosos. Editora Realize, 2017.

5. DE PAIVA JZ, DE OLIVEIRA RJF. A sociedade do espetáculo: uma autotradução como crítica. Non Plus, 2015; (7):139-155.

6. DE SAMPAIO RPA, FERREIRA RF. Beleza, identidade e mercado. Psicologia em Revista, 2009; 15(1):120-140.

7. DE SENA RMC, et al. A construção social do corpo: como a perseguição do ideal de belo influenciou as concepções de saúde na sociedade brasileira contemporânea. Mudanças, 2019; 27(1).

8. DE SOUZA MRR, et al. Droga de corpo! Imagens e representações do corpo feminino em revistas brasileiras. Revista Gaúcha de Enfermagem, 2013; 34:62-69.

9. GOETZ ER, et al. Representação social do corpo na mídia impressa. Psicologia \& Sociedade, 2008; 20:226-236. 
10. HEINZELMANN FL, et al. A tirania da moda sobre o corpo: submissão versus subversão feminina. Revista Subjetividades, 2014; 14(2):297-305.

11. LÔBO ILB, et al. Percepção da Imagem e Satisfação Corporal em Estudantes Universitários. Revista Brasileira de Cineantropometria \& Desempenho Humano, 2020; 22.

12. LOPES AF, DE MENDONÇA ES. Ser jovem, ser belo: a juventude sob holofotes na sociedade contemporânea. Revista Subjetividades, 2016; 16(2):20-33.

13. LOSS L, SANTOS CA. Perspectivas femininas sobre padrões de beleza no IFRS Campus Bento. Mostra TécnicoCientífica, 2019; 1.

14. MACHADO RC, NORONHA IL. Ditadura da beleza. Caderno Discente do Instituto de Ciências Jurídicas, 2011; 1(1):19-20.

15. NETO PP, CAPONI SNC. A medicalização da beleza. Interface-Comunicação, Saúde, Educação, $2007 ; 11: 569-584$.

16. PEREIRA TMA, LEITE MRB. A ditadura da beleza: a construção identitária feminina no discurso publicitário. ABRALIN, 2009.

17. STOLARSKI G, et al. Blogueiros fitness no Instagram: o corpo e o merchandising editorial de suplementos alimentares. Revista Eletrônica de Comunicação, Informação e Inovação em Saúde, 2018; 12(4).

18. SUENAGA C, et al. Conceito, beleza e contemporaneidade: fragmentos históricos no decorrer da evolução estética. UNIVALI, 2012.

19. VIEIRA CAL, BOSI MLM. Corpos em confecção: considerações sobre os dispositivos científico e midiático em revistas de beleza feminina. Physis: Revista de Saúde Coletiva, 2013; 23:843-861.

20. VISCARDI AW, et al. Narcisismo na sociedade do espetáculo: consumo e beleza feminina nas capas da revista Claudia. Revista Estação Científica, 2012; (7):01-20. 